\title{
Qualitative learning analytics to detect students' emotional topography on EduOpen ${ }^{1}$
}

\author{
Fedela Feldia Loperfido ${ }^{\mathrm{a}}$, Anna Dipace ${ }^{\mathrm{b}}$, Alessia Scarinci ${ }^{\mathrm{c}}$ \\ ${ }^{a}$ University of Foggia, Italy, feldia.loperfido@unifg.it, ORCID 0000-0003-2392-0021 \\ ${ }^{b}$ University of Modena Reggio Emilia, Italy, anna.dipace@unimore.it, ORCID 0000-0001-9826-073X \\ ${ }^{c}$ University of Foggia, Italy, alessia.scarinci@unifg.it, ORCID 0000-0002-3174-7137
}

\begin{abstract}
What emotions can students experience in digitally mediated learning processes? In this paper, we connect Learning Analytics to the Grounded Theory in order to analyse the emotional world of students of 11 courses within the EduOpen (www.eduopen.org) massive open online course (MOOC) platform. Namely, we have used NVivo 11 Plus software and have adopted a bottom-up process to analyse the forum dedicated to students' selfpresentation from all the courses. Proceeding with the analysis, we defined a set of categories composed of a three-level system. At a more general level, we have two dimensions that we named, respectively, 'Sentiments about shell' and 'Sentiments towards the pulp'. Each of these dimensions is composed of a number of 'child' categories and subcategories (which are the nodes in NVivo's language). After defining the entire set of categories and categorising all the texts (which was a circular process), we run some graphs on NVivo showing the hierarchical structure of the dimensions, the relations between the dimensions and the sources and the clusters of dimensions by coding similarity. The results show how some courses are composed of more negative or more positive sentiments (towards the topic and/or the logistic arrangement of the course) and how the motivation dimension characterises the broad emotional dimension of students heavily. In an evidence-based action-research perspective, these results provide interesting suggestions to personalise the learning activities proposed to students by EduOpen.
\end{abstract}

Keywords: learning analytics, grounded theory, MOOCs, emotional experience, NVivo 11 Plus

\section{Theoretical framework}

This paper aims at exploring the emotional dimension that adult students feel when they participate in massive open online courses (MOOCs). What does this mean? What psychoeducational aspects does this oneline-long pretention involve? What characteristics of educational digital environments should we take into account? To answer these questions, we need to refer to the following intertwined topics: 1) What we mean by 'emotion'; 2) What relationship emotions and learning have with each other; 3) How this possible relation can be characterised in online learning environments and, more specifically, during students' participation in MOOCs; 4) How this online-mediated emotional dimension can be analysed. In this paragraph, we examine the first three points and introduce the fourth one, which is described further in the paragraphs devoted to the research.

\footnotetext{
${ }^{1}$ This article has been developed jointly by the authors. More specifically: Anna Dipace wrote the following sections: 1. Theoretical framework; 2. Aims; Fedela Feldia Loperfido wrote the following sections: 3. Context and Data; 4. Method of Analysis; 5. Results; Alessia Scarinci wrote the following sections: 6. Conclusions; 7. Implications and future directions.
} 
Speaking about feelings and emotions from a general and classical perspective, human beings can feel universal emotions, such as anger, disgust, fear, happiness, sadness and surprise (Ekman, 1999) or joy-sadness, anger-fear, trust-distrust and surprise-anticipation (Plutchik, 2013). From this theoretical perspective, emotions are discrete, i.e. the emotional experience is composed of small sets of specific universal and basic emotions. These are common to all human beings, regardless of the sociocultural aspects that shape people. At the same time, other and even opposite theoretical approaches suggest that emotions are featured by several dimensions changing over space and time. For example, the degree of positivity or negativity felt about an emotion, as well as the physical response related to it, can be two of the possible dimensions forming emotions (Lutz \& AbuLughod, 1990).

However, by overcoming this panorama, we need to answer this question: 'How can we define and understand emotions at a more specific level?' According to Zembylas (2008), there is no agreement about what an emotion is and what it is characterised by. Indeed, emotions can be understood at least from three different perspectives: 1) Emotions as private and belonging to an intimate experience, as defined by psychodynamic approaches. In this case, the emotions that learners feel about their learning experiences are highly influenced by the early childhood relationships they had with caregivers. Learning and teachers represent symbolic mirrors on which students unconsciously project the primitive emotions they felt within their first primary caring relations (Pergola, 2017). 2) Emotions as sociocultural phenomena, as perceived by social constructionist approaches. Following this approach, emotions are situated in the specific contexts in which people feel them and are built through the mediation of cultural values, rules and tools (Lynch, 1990). 3) Emotions as described by interactionist approaches, which transcend the dichotomies (e.g. mind/body, individual/social) established in the previous two points and aim at bridging their differences. Even if there is no common definition of emotions, scholars claim that they are not separated from the learning experience (Lehman, 2006; Lipman, 1991).

Indeed, Ez-zaouia and Lavoué (2017) explain that learning can be more successful when both teachers and potential tutors try to minimise negative emotions and support the positive ones, especially in online learning environments. The interconnection between learning and emotions is still being developed, particularly in Western culture and in relation to online learning contexts (Zembylas, 2008). However, the interest about what teachers, students and tutors feel when they experience mediated teaching/learning processes is growing. Sometimes, online learning has been defined as 'cold' and automatic (Mac Fadden, 2007), but several studies observe that the emotional experience in online learning activities does not imply necessarily the feeling of coldness and distance from each other. Rather, it entails a broader spectrum of feelings, both positive and negative. Indeed, very often, people feel they receive help from technology in their jobs or in collaborative and communication processes.

Coherently with this, for instance, communities of inquiry model (Garrison, Anderson \& Archer, 2000) suggest that students can be organised in digital community-mediated learning experiences characterised by cognitive presence, social presence, teaching presence and emotional presence (Cleveland-Innes \& Campbell, 2012). Cognitive presence is the ability of students to build meaning through reflections and discourse. Social presence is the way students perceive themselves and connect with each other, both socially and emotionally. Teaching presence is composed of designing, facilitating and recommending activities that support the construction of a meaningful learning experience. Emotional presence is understood as the 'emotional expression part of being socially present online' (ibidem, p. 272). Therefore, this presence involves the need of being in a socially rich online system, within which the crucial points are the interactions and the perception of having a role in relation to other people. In this plethora of different views, MacFadden (2007) tries to summarise the main points describing the emotional dimension in relation to online learning environments. He suggests that educators and learners usually have contradictory biases against emotions in learning. They can, indeed, perceive that emotions are disruptive for learning or, on the contrary, extremely productive. As claimed by recent research in neuroscience, emotions can usually modulate attention, motivation and reasoning. Particularly, positive feelings (e.g. enthusiasm, joy, etc.) can stimulate creativity, flexible thinking and high performance. In any case, we can define that 'Emotions are too complex to be categorized as strictly positive and negative [...] Learning involves a wide range of emotions' (ibidem, p. 99). Therefore, how can the complexity of emotions related to online learning environments be grasped?

In this paper, we try to connect both Learning Analytics (Siemens \& Long, 2011) and Grounded Theory approaches (Backman \& Kyngäs, 1999). Learning analytics consists in measuring, collecting, analysing and 
reporting data about students and the contexts through which they learn. The aim of learning analytics is to understand, personalise and optimise both learning and the environments in which this occurs. Learning analytics is used mainly in learning contexts mediated by the use of digital environments, since they can produce a huge amount of data on the traces that each student or entire groups of learners leave online, such as successful activities, difficult experiences and so on (Rienties \& Rivers, 2014). In turn, emotional analytics can recognise students' emotions and, in turn, predict the level of success of a course, obtain emotional feedback on the content of courses, analyse and improve teachers' strategies, improve users' experience on digital platforms (Liu et al., 2016), bridge the gap that students sometimes perceive between their learning goals and digital skills, as well as meet learners' motivation.

On a general layer, sentiment analysis can be used. It is also referred to as sentiment classification, sentiment mining, review mining, subjectivity analysis, opinion mining or appraisal extraction; classification of polarity deals with the computational treatment of opinion and subjectivity in text. Sentiment analysis aims at determining a speaker's decision about a topic considering both negative and positive sentiments that people have about it. However, this analysis does not suggest how we can understand emotions on a more specific level. As far as this point is concerned, Cleveland-Innes and Campbell (2012) approach the emotional experience of students through the Grounded Theory. They analyse the content of texts looking for emotions, and they develop a grid thereof (from the text to the categories). In this case, the focus of the researcher or the teacher is not "emotion "per se" but emotion talk, i.e. how emotion discourses are used (e.g. by adult learners), what role these discourses play (e.g. in online learning) and how they change (if they do so)' (Zembylas, 2008, p. 74). In other words, we claim that both a general analysis and a more specific level of analysis are needed to observe the features of emotions in learning activities. As suggested by MacFadden (2007), emotional topography can be described as the range of emotions experienced by students in a specific online class.

\section{Aims}

This study intended to achieve the following:

- To explore the emotional processes experienced by students during the participation in MOOCs proposed by the University of Foggia within the EduOpen project (http://www.eduopen.org);

- To personalise the learning activities, according to students' emotional experience.

\section{Context and Data}

This research was supported by the UniFG Tutoring - UniTutor project and the context of analysis is EduOpen, an international Moodle platform led by the University of Foggia (IT). EduOpen is implemented by 17 Italian universities and several foreign partnerships. It started in 2014 and is an action-research project periodically rearranged on the basis of evidence-based methods. Until now, it has involved $>70,300$ learners from all over the world and has proposed 140 courses. Indeed, the activities of EduOpen comprise online courses loaded on the Moodle-based platform www.eduopen.org.

Through a micro-perspective, each course refers to a specific topic (e.g. math for beginners, animals, English and so on) and is managed by a university teacher and an online tutor of the EduOpen team. Furthermore, at the end of any course, students receive a participation certificate, also called the open badge or European Credit Transfer and Accumulation System (ECTS). More specifically, each course lasts 3-5 weeks and is composed of the following:

- a self-presentation forum, where students usually write down a post about themselves, the place where they live, the wishes and expectations they have about the course and so on;

- a number of MOOC videotape recordings by the teacher related to the topic of the course;

- another forum where students can ask further explanations to the teacher;

- an evaluation section, where students fill in online tests during or at the end of the course.

All the courses are categorised and collected in different fields (such as literature, science and so on), in several pathways (an ensemble of courses connected with each other by a main theme) and/or in the catalogue that a specific University partner proposes. In this paper, data are characterised by the self-presentation forums of all the courses (numbering 11) managed by the University of Foggia (IT). Table 1 specifically shows the courses and the number of participants for each. Namely, in the 'Assigned people' column, the number of 
students initially enrolled in the course is shown; in the column 'Completed people', the number of participants who completed the entire course is shown. Therefore, we have specifically looked at the emotional experience related to each course and the ensemble of the courses proposed by the University of Foggia.

Table 1. MOOC courses of the University of Foggia

\begin{tabular}{|c|c|c|}
\hline Course & $\begin{array}{l}\text { Assigned } \\
\text { people }\end{array}$ & $\begin{array}{l}\text { Completed } \\
\text { people }\end{array}$ \\
\hline Gli animali... chi sono? Chi siamo? (Animals) & 264 & 83 \\
\hline I 'come' e i 'perché' della storia e della filosofia del diritto (The how and why of history & & \\
\hline and philosophy of Law) & 377 & 94 \\
\hline Introduzione alla Fisica (Physics) & 198 & 26 \\
\hline La storia, le storie (Knowing History) & 1053 & 239 \\
\hline Matematica per principianti: insiemi e operazioni elementari (Math for absolute & & \\
\hline beginners) & 1036 & 263 \\
\hline Pedagogia ed Educazione: concetti base (Pedagogy and education, basic concepts) & 794 & 147 \\
\hline Percorsi di storia della letteratura italiana: l'epica cavalleresca (History of Italian & & \\
\hline Literature) & 850 & 175 \\
\hline Pillole di Biochimica (Biochemical pills) & 238 & 63 \\
\hline $\begin{array}{l}\text { Pre-corso di Matematica generale: Equazioni e Disequazioni (Course of general } \\
\text { mathematics) }\end{array}$ & 470 & 99 \\
\hline $\begin{array}{l}\text { Principi di Patologia Generale: danno cellulare, infiammazione, riparazione, oncologia } \\
\text { (Basic general pathology) }\end{array}$ & 174 & 20 \\
\hline Promozione turistica attraverso i media digitali (Tourism marketing trough digital media) & 336 & 66 \\
\hline Total & 5790 & 1275 \\
\hline
\end{tabular}

\section{Method of analysis}

According to the Grounded Theory approach, we proceeded as follows:

1. We first created a general grid of analysis, composed of the two following general dimensions, 'Positive sentiments' and 'Negative sentiments', which referred to learning experience in the digital context.

2. We categorised the texts through qualitative content analysis (Mayring, 1997) by using NVvivo 11 Plus. The unit of analysis corresponds to the unit of meaning. Instead of looking at physical linguistic units (words, sentences and paragraphs), we used individual themes as the unit of analysis. Therefore, a unit of meaning represents the expression of an idea, an argument chain or a discussion topic (Chi, 1997; Henri, 1992). However, the themes were circularly built as the analysis went ahead.

3. We generated further dimensions and their specific categories, which emerged from the interaction among the grounded approach, the theoretical concepts and the students' words.

4. We further discussed in teams the building of the grid and the categorisation.

5. We then checked the categorisation according to the team discussion.

6. We finally analysed the nodes (the categories of the software) using NVivo 11 Plus.

\section{Results}

During the analysis, we realised that the first version of the grid required to be enriched considerably. Therefore, we created a double grid, which would grasp three levels of the students' emotional experience with the EduOpen courses of the University of Foggia. We defined two general dimensions: 1) Sentiments grasping what students felt about EduOpen, its services and the arrangement of the courses; 2) Sentiments observing the feelings related to the topic of the specific course in which students participated. In other words, the first dimension is about the feelings towards the digital environment, the concept of EduOpen and the organisational arrangement of the activities. The second one refers to the feelings for the topic of the specific course. Each dimension is, then, characterised by other specific subcategories, which are further described later in the article.

For us, the first crucial result is that the emotional experience of the students in this context is represented by a wide and deep topography of two main objects stimulating students (the architectural aspects of the courses and the contents they propose). Each of this macro-dimension is characterised by other subcategories. We describe the dimension of the sentiments towards those aspects (organisational, tools-related, technological, etc.) that we name 'Shell', since they represent the contextual and structural features of the learning activities. Subsequently, we describe the dimensions of the emotions towards those content aspects that are specific of each 


\section{Qualitative learning analytics to detect students' emotional topography on Eduopen \\ Loperfido, Dipace, Scarinci}

course and which we name 'Pulp', since they represent what is inside the external structure of the digital environment.

Before we move on, we would like to specify that we have been using the label 'Sentiments', instead of feelings or emotions, without referring to any specific theoretical approach or conceptual differentiation. We use it just for our agreement, since a more mindful choice would imply a theoretical expatiation that is beyond the scope of this paper.

\subsection{Sentiments about the shell}

The definition of these feelings is inspired by the so-called 'Sentiment analysis' method, also known as opinion mining. It is usually understood as the method used to extract subjective opinion and information from natural language and texts. To achieve this, the method is usually used to analyse social media for marketing processes or for supporting clients. Furthermore, sentiment analysis usually implies the reference to two categories, which are negative sentiments and positive sentiments towards the object that is analysed (e.g. a TV show, a political campaign, etc.). The NVivo software is based on this principle and enables, by default, to categorise texts referring to some child categories (namely, to subcategories), as well. These are called 'Moderately' and 'Very' negative or positive sentiments. Therefore, we started the analysis by using the NVivo settings.

However, as we have previously disclosed, we realised that the students' emotional experience was much more complex than a simple distinction between negative/positive and moderately/very sentiments roughly associated with the overall learning experience. Since the sentiments towards the shell of the experience were not so rich and frequent, we preferred using the dry and simple categorisation set by NVivo. It is important to keep in mind that the process of the grid enrichment was a dynamic and circular one. Indeed, as we went ahead with the analysis, we defined new categories referring to the two main dimensions through the Grounded Theory method. As clarified in the 'Method of analysis' section, after creating the final grid of analysis and making the categorisation, we checked both the grid and the first categorisation with a team discussion, until we reached a total agreement on the two of them. In the end, we analysed the nodes and their relationships with the sources (the texts of the forum) by elaborating some graphs through NVivo 11 Plus. In this paper, however, to clearly show the results about the shell and the pulp of the experience, we present them one dimension after the other, dimension by dimension.

Figures 1 and 2 show the hierarchical parent-child relationship graphs of the categories about the shell of the course, and some examples of texts related to each category.

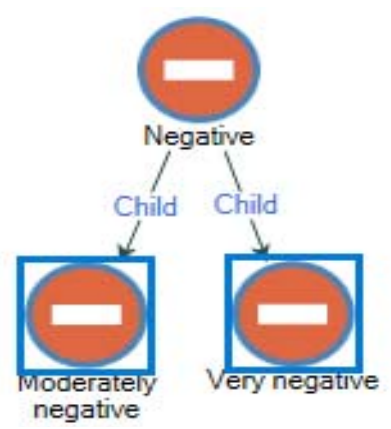

Fig. 1. Parent-child relationship graph about the negative sentiments towards the shell of the learning experience.

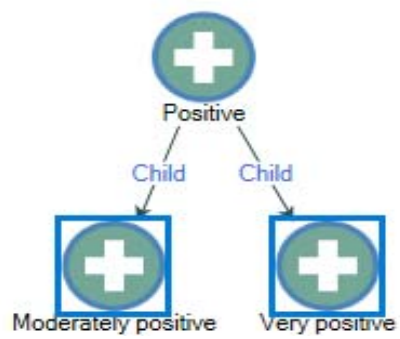

Fig. 2. Parent-child relationship graph about the positive sentiments towards the shell of the learning experience. 
The following graphs (Figures 3-6) and their respective descriptions show the analysis we made. Figure 3 suggests that, as for the general dimension 'Sentiments about the shell', the category 'Positive sentiments' is far more prominent than the one about negative sentiments. Furthermore, moderately positive sentiments are present to a greater extent in the texts than the highly positive ones. Indeed, the dark orange section represents 'Positive sentiments' as a whole, whereas the dark blue one represents 'Negative sentiments'. The smaller light orange section indicates the highly positive sentiments; the smaller, light blue section denotes the highly negative sentiments.

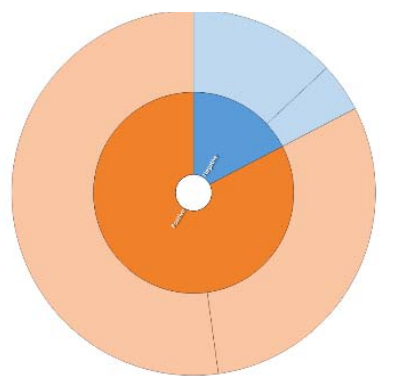

Fig. 3. 'Sentiments about the shell' hierarchical graph.

Figure 4, instead, shows what the relations between the nodes and the sources are. As can be seen, in eight forums referring to the respective courses (Biochemical pills, Math for absolute beginners, Law history and philosophy, Animals, Knowing History, History of Italian literature, Course of general mathematics and Tourism marketing through digital media), students express both positive and negative sentiments about the structure of the course and/or EduOpen as a learning experience. Furthermore, in the document about 'Pedagogy and education, basic concept' course, there are references to just positive sentiments, whereas, in the course about 'Physics' and 'Basic general pathology', there are no expressions of sentiment. Indeed, the red circle represents Negative sentiments, whereas the green circle represents Positive sentiments. The arrows show the relationship existing between each dimension and the forum of the specific course, as well as whether there are coded units of the text that uses the dimensions.

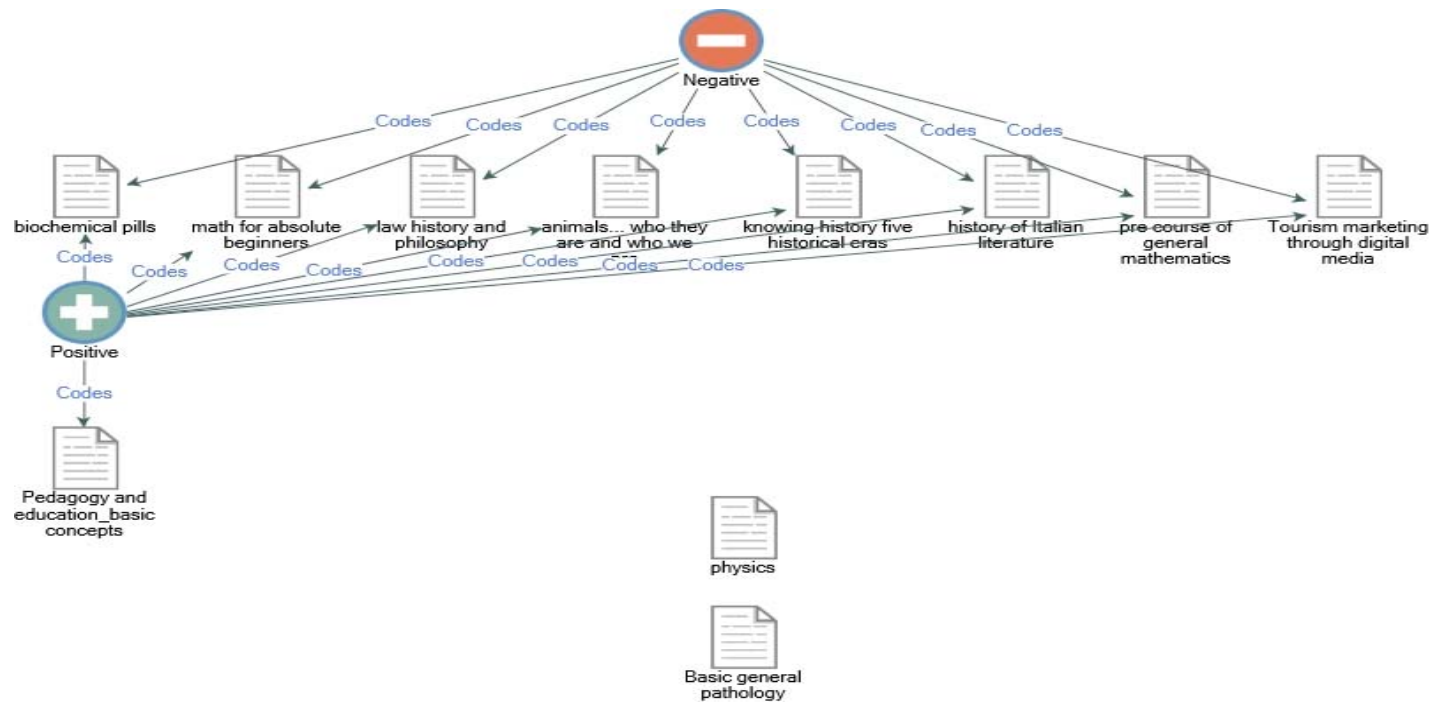

Fig. 4. 'Sentiments about the shell - sources' project map.

\subsection{Sentiments towards the pulp}

The 'Sentiments towards the pulp' dimension was finally shaped by a complex structure of categories. On the middle level, we grasped the three categories 'Motivations', 'Negative sentiments' and 'Positive sentiments' (not to be confused with the two namesake categories 'Positive' and 'Negative sentiments' about the digital experience in EduOpen already described).

'Motivations' refers to a category exploring a more cognitive dimension, even implying the students' expectations about the contents of the course and the reason why they are going to attend the course. Indeed, it is 


\section{Qualitative learning analytics to detect students' emotional topography on Eduopen \\ Loperfido, Dipace, Scarinci}

composed of seven specific or 'child' categories. The 'Motivation category' is situated within the emotional dimension. At the same time, we define them as cognitive components since they refer to the expectations and the rational causes leading students to both enrolment and participation. Differently, the 'Negative sentiments' category is about the feelings that students feel towards the content of the course and is composed of five specific or 'child' categories. 'Positive sentiments' is about the good feelings that students have towards the content proposed in the course and is shaped by five specific or 'child' categories. In Table 2, we describe all the categories under 'Sentiments towards the pulp' (a graph similar to Figures 1 and 2 would be more impressive, but we thought the table would be more effective).

Table 2. Dimension, categories and subcategories

\begin{tabular}{|c|c|c|}
\hline Dimension & Category & $\begin{array}{l}\text { Subcategory (and eventual description in case of } \\
\text { labels that cannot be easily understood) }\end{array}$ \\
\hline \multirow[t]{3}{*}{$\begin{array}{l}\text { Sentiments } \\
\text { towards the pulp }\end{array}$} & $\begin{array}{l}\text { Motivations (the reasons why people participate } \\
\text { in the course they enrolled) }\end{array}$ & $\begin{array}{l}\text { Deepen knowledge (to go in depth into the topic the } \\
\text { course refers to) } \\
\text { Home learning (to participate because you can attend } \\
\text { the course while staying at home) } \\
\text { Innovative methods (tried through the MOOC } \\
\text { structure of the course) } \\
\text { Mind training } \\
\text { Old knowledge renewal } \\
\text { Practical effects (in daily job activities) } \\
\text { Support to learning (of other contemporary learning } \\
\text { experiences) }\end{array}$ \\
\hline & $\begin{array}{l}\text { Negative sentiments (the bad feelings students } \\
\text { have towards the contents of the course) }\end{array}$ & $\begin{array}{l}\text { Confusion } \\
\text { Fear } \\
\text { Feeling of trouble } \\
\text { Nostalgia (about past learning experiences on the } \\
\text { same topic) } \\
\text { Feeling of incompleteness }\end{array}$ \\
\hline & $\begin{array}{l}\text { Positive sentiments (the good feelings students } \\
\text { have about the contents of the course) }\end{array}$ & $\begin{array}{l}\text { Discovery and curiosity } \\
\text { Enthusiasm } \\
\text { Feel of interest } \\
\text { Hope (to better understand the contents, in opposition } \\
\text { to past experiences) } \\
\text { Passion }\end{array}$ \\
\hline
\end{tabular}

What about this dimension? Figure 5 shows that the 'Motivation' category is the richest one, followed by 'Positive sentiments' and then by 'Negative sentiments', suggesting that cognitive aspects have a higher incidence in the texts. Indeed, the blue section is about Motivations, the grey section is about Positive sentiments and the orange section is about Negative sentiments towards the topic.

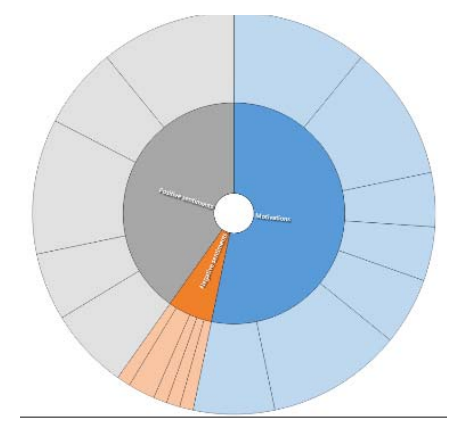

Fig. 5. 'Sentiments towards the pulp' hierarchical graph.

Figure 6 describes the connections existing between the codes and the sources. As can be seen, the 'Motivation' category is related to all the sources, whereas the 'Positive sentiments' category is used in the texts of all the courses except in 'Physics.' Negative sentiments are involved in just three sources (Math for absolute beginners, Law History, Pedagogy and Education: Basic concepts). 


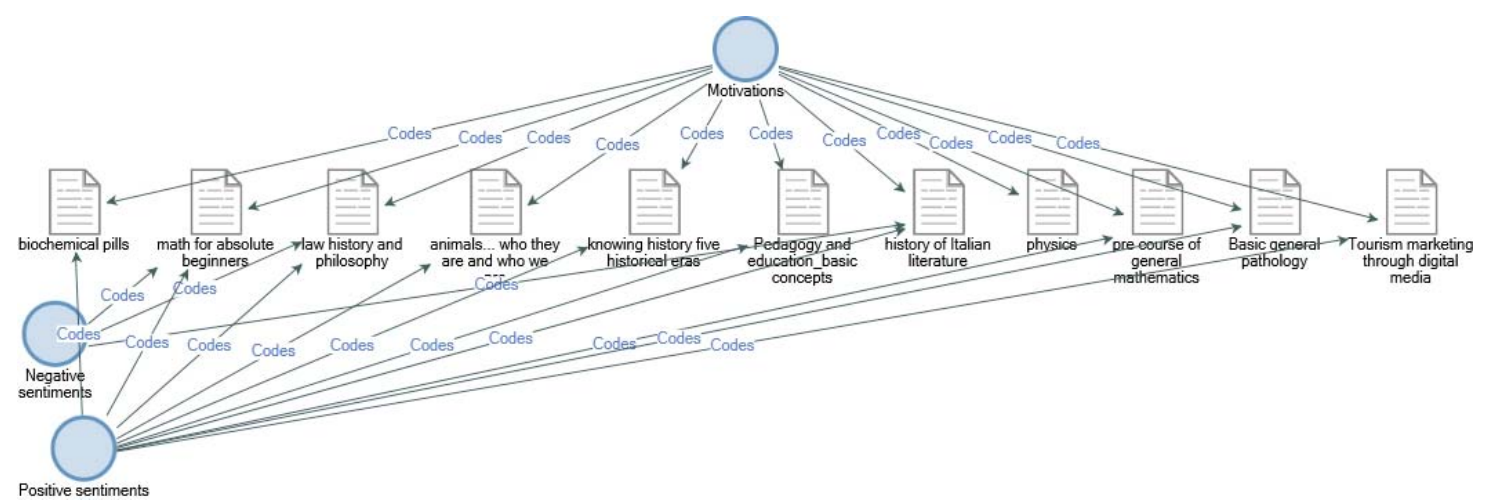

Fig. 6. 'Sentiments towards the topic - sources' project map.

Finally, we clusterised both sources and codes by coding similarity (Figures 7 and 8 ). It emerged that 'Motivation' and 'Positive emotions' are similar categories and that 'Physics' and 'Basic genetic pathology' are the most distant sources from the others.

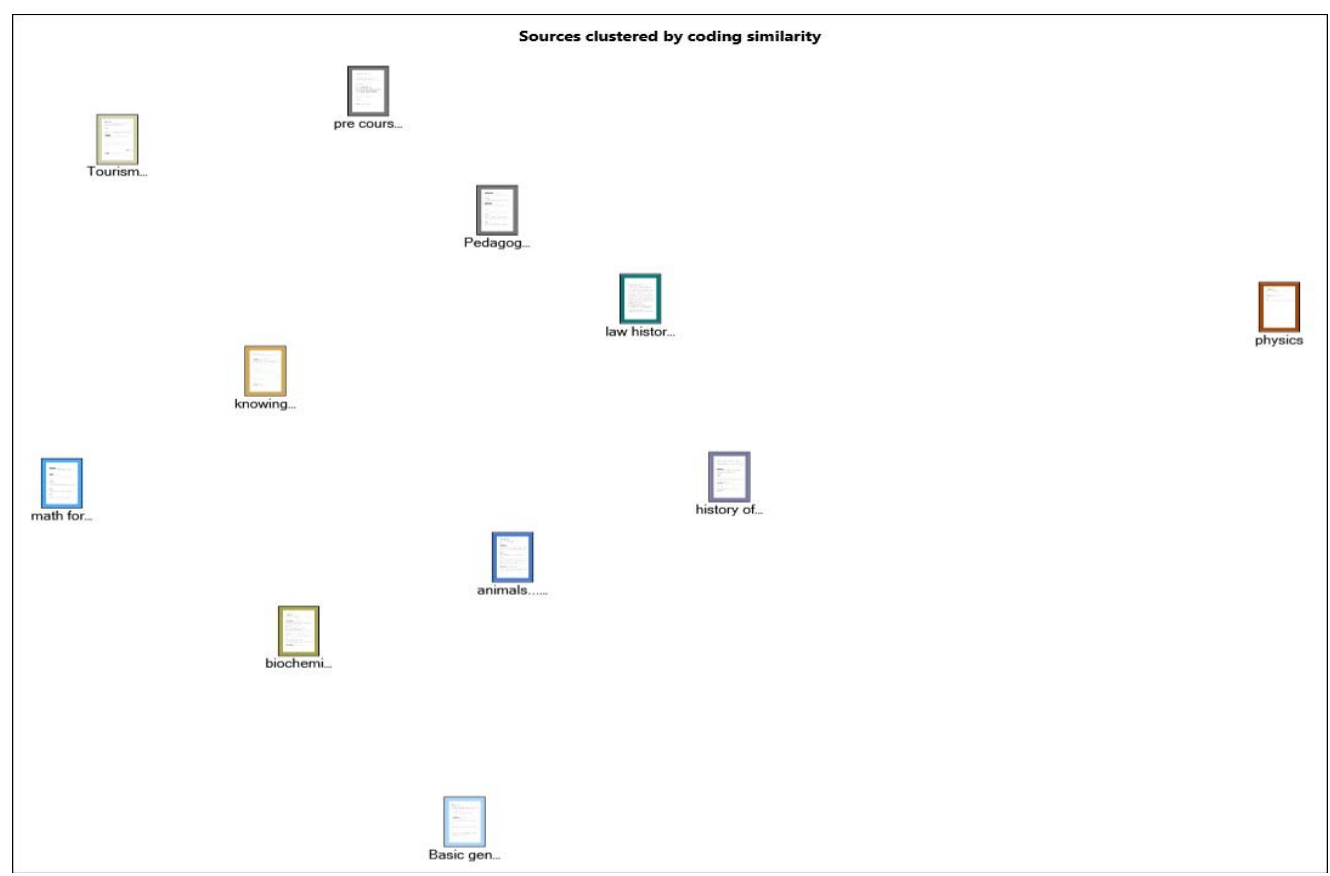

Fig. 7. Cluster analysis of courses. 


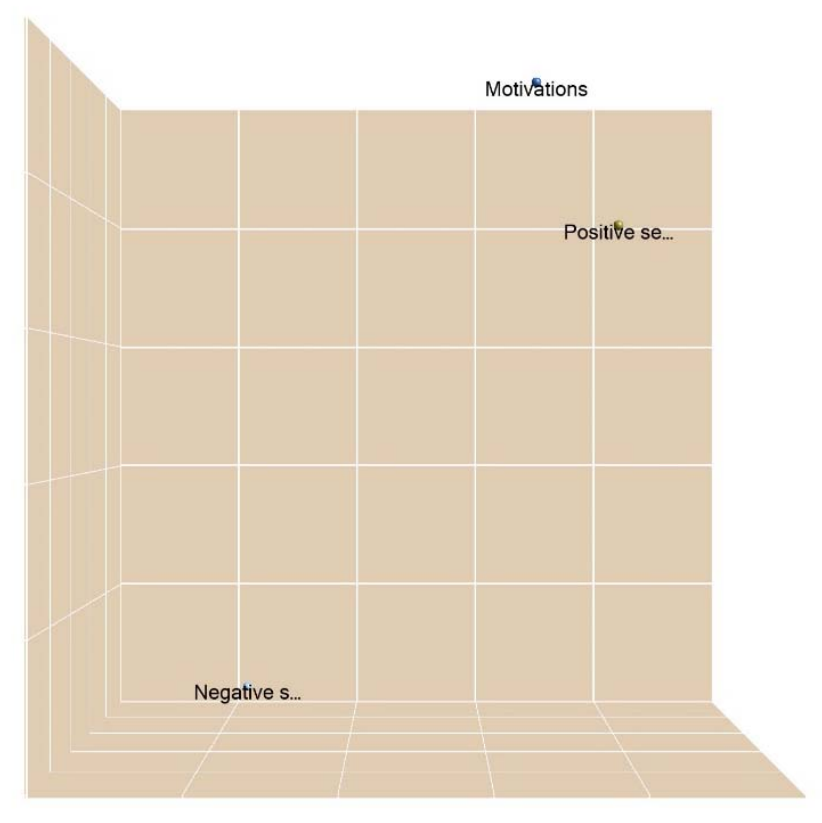

Fig. 8. Cluster analysis of nodes.

\section{Conclusions}

As Liu and Zhang (2016, p. 17) affirm, 'MOOC offers a variety of interactive ways in which the course comment panel is used to express the students' opinions and feelings. These comments generally contain some learning problems, attitudes toward the course or the platform support, etc.' Furthermore, MacFadden (2007) claims that, when taking online courses, students feel various emotions arising from the daily, subjective, interactive and specific experience. Each online learning context is characterised by its own emotional life, which is generated by people during the activities. We wish to stress that this emotional dimension is sometimes conscious and explicit, but very often, it is unconscious and implicit.

Participants are not always aware of their sentimental inner world related to the learning context, to their story as students, to their past experiences as well as to the ways they affect the present ones. In other words, the learner's emotional life is usually featured by what they consciously feel during the activity itself, which implies all those thoughts describing negative/positive sentiments related to learning. At the same time, there is an inner and unconscious dimension that is not that easily accessible and which affects the learning experience in terms of behaviours, emotions, relationships, efforts and results. Far from analysing all these emotional levels, in this contribution, we focussed on the description of the emotional topography emerging from the notes that students posted in the presentation forums related to the MOOCs managed by the University of Foggia within the EduOpen project. We used a Grounded Theory approach to observe both positive and negative emotions of students, as well as to detect the micro-emotional culture in the MOOC ones.

Therefore, we first defined the general dimensions and then we compiled the emotional topography of the context. What can we say in conclusion? First, the emotional experience of students seems really broad and substantial. Therefore, we had to split it among the sentiments about technology, the organisation of activities, the logistic choices of teachers (what we called 'shell') and the sentiments about the content of each course (what we called 'pulp'). Ritella, Martinelli, Loperfido and Ligorio (2015) suggest that students can be involved in an instrumental genesis experience, which is a sense-making process through which they try to associate their own meanings to the digital environments and to appropriate and internalise them. This process is functional to the implementations of the learning activities and can be repeated during the course. When students have some kinds of negative experiences while using the platform (e.g. they are in trouble using a tool or feel uncomfortable about the way the educational materials are organised in the digital environment), they tend to spend time, 
resources and efforts to give sense to this aspect since they internalise the use of the tool. When people use any new instrument for learning, especially a digital one, this is a very crucial process.

Therefore, we think that the expression of emotions about the shell of the courses represents a need for students, since it supports the problem-solving practical issues, but also the process of making sense and internalisation of the technological tool. Positive sentiments constitute the other side of the coin, since they can express satisfaction, enthusiasm and happiness, but also a feeling of comfort for the use of the internalised tool. In other words, on a superficial (and even functional) level, the sentiments about the shell of the courses give feedback about the effectiveness of the EduOpen organisation. However, on a deeper level, they can also give hints about the internalisation of the tool and can increase the chances that students have to focus on the learning activities instead of making sense of the process about technology. Furthermore, on a discursive level, the very negative sentiments about the shell are lesser than those moderately negative. This result gives an important feedback about the organisation of the courses, since students feel really angry or unhappy just few times because of the temporary malfunction of the platform.

Regarding the sentiments for the course contents, some further interesting results emerged. First, the complexity of the emotional experience of the students emerges. The presence of both motivational and purely emotional aspects discloses this complexity, further sustained by the three-level structure of the dimensions. During the analysis of the texts, we realised that a multilevel structure was needed to describe the emotional experience. Therefore, a general dimension was categorised and composed of three subcategories, each of which was composed of a number of child categories. At a motivational level, students are moved to participate in the courses by intrinsic (e.g. to deepen their knowledge) or extrinsic (e.g. to have a support for the university exams) aspects.

At the same time, the 'Motivation' category has a prominent space in the hierarchical graph on the emotions connected to the topic of the course. The 'Negative sentiments' and 'Positive sentiments' categories are composed of several micro-emotions (e.g. fear, feeling of trouble, enthusiasm, passion and so on). What sounds interesting in this research is the relationship that NVivo shows between the dimensions and the specific courses delivered on EduOpen. In fact, it seems that, during all the courses, students may feel different motivations and emotions, stressing the positive ones more. Furthermore, by looking at the cluster analysis, it emerges that the 'Motivation' and 'Positive emotions' dimensions are more similar to each other. It seems, therefore, that they usually occur together in the texts and that there is a relation between them. Probably, the enrolment in MOOCs is tightly related to the intrinsic motivations and to the idea of lifelong learning (or learning experiences), which are intentionally chosen by students.

By going in-depth in the several courses, it emerges that the 'Motivation' dimension is used in all the texts. Probably, this result - and the fact that in the hierarchical graph, this dimension is the most relevant one - is due to the nature of the analysed forums. Indeed, they are the initial ones, and students are asked by tutors to express their expectations and objectives about the participation in the course. These themes are very strongly related to the motivational process, and this justifies the presence of the motivational aspect in every course. Therefore, by looking at the sources project map, we find it interesting that the courses entitled 'Math for absolute beginners', 'Law history and philosophy' and 'History of Italian Literature' elicit negative sentiments about the topic. Differently, the 'Physics' course is the only one without any kind of emotions expressed (its differentiation is showed by Figure 7 too). These results seem interesting because they suggest the following: 1) there is a differentiation between the emotional experiences for the different courses; 2) there is a course that does not seem to elicit the expression of any emotions; and 3) the expression of negative emotions is limited to three courses.

From this study, we conclude that the entire set of categories reviewed in this context shows how complex is the emotional experience of students participating in these MOOCs. This is not just due to the number of categories shaping the set but also due to the three levels characterising it, the relationships between them and the contextualised value that they have in the different educational experiences. Finally, they differ in relation to the courses.

\section{Implications and future directions}

One of the main objectives of learning analytics is personalising the learning experience, arranging the activities according to students' educational needs, their paces, expectations, motivations, etc. The present work 
is a preliminary study in this direction. Even though we did not analyse the learning path of each student, we observed the trend of each course to rearrange the activities proposed by EduOpen at the University of Foggia. We do claim that looking at the emotional experience can strongly support the organisation of efficient learning activities, connecting the educational aims with the way learners' experience them. In fact, the main implication of this research is represented by several ongoing meetings with the teachers delivering the courses to further explore some aspects that emerged in this research and to organise future courses.

It is important to keep in mind that MOOC courses are characterised by a common main structure. Therefore, the following questions that need to be explored arose from these first results: is there a correlation between the student-teacher virtual relationship and the students' emotional experience? Is there a topic-sentiment relationship? Are there predictable correlations between these elements? Can a final forum be used to involve students in expressing their emotions at the end of the course, as well? What are the emotions felt about the relationship with teachers, the interactions with other students, the evaluation system and the consequence of the learning experience on EduOpen?

Several meetings with the teachers are going to be planned in order to train them in the stimulation and elicitation of those emotional experiences that can support the efficacy of learning. Another implication of this study is the implementation of new management tools in the platform. Indeed, it is not possible to detect the students' age, sex and time devoted to each activity; researchers, teachers and tutors cannot explore deeper statistics about the traces students leave online. Therefore, EduOpen is integrating new tools supporting the personalisation of learning. Besides the practical implications, this study has inspired further and more specific analysis to give justice to the complexity of the students' emotional presence. The ensuing studies will analyse the possible statistical correlation in the codes-dimensions and codes-sources relationships, as well as the direction of such relations. Lastly, we will analyse the forums of other EduOpen courses in order to broaden the study to the entire macro context of EduOpen, as well as to create methodological tools connecting the usual quantitative perspective of learning analytics and the qualitative dimension shaping the emotional experience of students.

\section{References}

Ritella, G., Martinelli, M., Loperfido, F. F., \& Ligorio, M. B. (2015). Tecnologie (in)visibili: appropriazione in un percorso di training professionale. Tecnologie Didattiche, 23 (1),19-25.

Backman, K., \& Kyngäs, H. A. (1999). Challenges of the grounded theory approach to a novice researcher. Nursing \& Health Sciences, 1(3), 147-153.

Chi, M. T. (1997). Quantifying qualitative analyses of verbal data: A practical guide. The journal of the learning sciences, 6(3), 271-315.

Cleveland-Innes, M., \& Campbell, P. (2012). Emotional Presence, Learning, and the Online Learning Environment. The international Review of Research in Open and Distance Learning, 13, 4, pp. 269-292.

Ekman, P. (1999). Basic Emotions. In T. Dalgleish, \& M. Power (Eds.), Handbook of Cognition and Emotion (pp. 45-60). SF: John Wiley \& Sons Ltd.

Ez-Zaouia, M., \& Lavoué, E. (2017, March). EMODA: a tutor oriented multimodal and contextual emotional dashboard. In Proceedings of the Seventh International Learning Analytics \& Knowledge Conference (pp. 429-438). ACM.

Garrison, D. R., Anderson, T., \& Archer, W. (2000). Critical inquiry in a text-based environment: Computer conferencing in higher education. The Internet and Higher Education, 2, pp. 1-19.

Henri, F. (1992). Computer conferencing and content analysis. In Collaborative learning through computer conferencing (pp. 117-136). Springer, Berlin, Heidelberg.

Lehman, R. (2006). The role of emotion in creating instructor and learner presence in the distance education experience. Journal of Cognitive Affective Learning, 2(2), pp. 12- 26.

Lipman, M. (1991). Thinking in education. Cambridge: Cambridge University Press.Liu, Z., Zhang, W., Sun, Jianwen, Cheng, H. N.H., Peng, X., \& Liu, S. (2016, September). Emotion and Associated Topic Detention for Course Comments in a MOOC Platform. In Proceedings of the International Conference on Educational Innovation through Technology (EITT) (pp. 15-19).

Lynch, O. M. (Ed) (1990) Divine passions: the social construction of emotion in India (Berkeley, CA, University of California Press). 
Lutz, C. \& Abu-Lughod, L. (Eds) (1990) Language and the politics of emotion (Cambridge, Cambridge University Press).

MacFadden, R. (2007). The forgotten dimension in learning: Incorporating emotion into web-based education. Journal of Technology in Human Services, 25(1/2), 85-101.

Mayring, P. (1997). Qualitative Inhaltsanalyse. Weinheim: Deutscher Studien Verlag.

Pergola, F. (2017). Un insegnante quasi perfetto. Ascoltare la relazione per crescere insieme. Roma: Franco Angeli.

Plutchik, R. (2013). Emotion: Theory, research, and experience. In R. Plutchik \& H. Kellerman (Eds.), Theories of Emotion (pp. 10-24). New York: academic Press.

Rienties, B., \& Rivers, B. A. (2014.). Measuring and understanding learner emotions: evidence and prospects. Learning Analytics Review, 1, pp. 2-30.

Siemens, G., \& Long, P. (2011). Penetrating the fog: Analytics in learning and education. EDUCAUSE review, 46(5), 30.

Zembylas, M. (2008). Adult learners' emotions in online learning. Distance Education, 29(1), 71-87. 